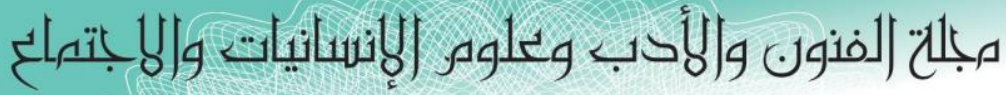

Journal of Arts, Literature, Humanities and Social Sciences

ISSN online: 2414 - 3383

ISSN print: 2616 - 3810

العدد (39) ريران - يونيو 2019

\title{
Comparison between four Methods to Construction Number of Defectives Control Chart
}

\author{
Dler Hussein Kadir \\ Department of Business Administration, Cihan University-Erbil, Kurdistan Region, Iraq \\ Department of Statistics, Salahaddin University-Erbil, Kurdistan Region, Iraq
}

Dlshad Mahmood Saleh

Department of Business Administration,Paitaxt Private Technical Institute ,Erbil, Kurdistan Region, Iraq Department of Statistics, Salahaddin University-Erbil, Kurdistan Region, Iraq

\section{Dashty Ismil Jamil}

Department of Health Administration, Lebanese French University -Erbil, Kurdistan Region, Iraq

\begin{abstract}
A quality control chart (also called process chart) is a graph that shows average for the data (output) or the product fall within the common or normal range of variation if the process is under statistical control. The existing study draws Comparison between four methods to construct Number of Defectives Chart. We compare methods to obtain the Number of Defectives chart based on Six sigma, which this makes the method much better than other methods, because the distance between control limits for Number of Defectives chart is based on six sigma which that has the smallest comparison properties than other methods, and that the process is out of control for all charts.
\end{abstract}

It is proposed that the six sigma should be used when monitoring and detecting out of control cases. 


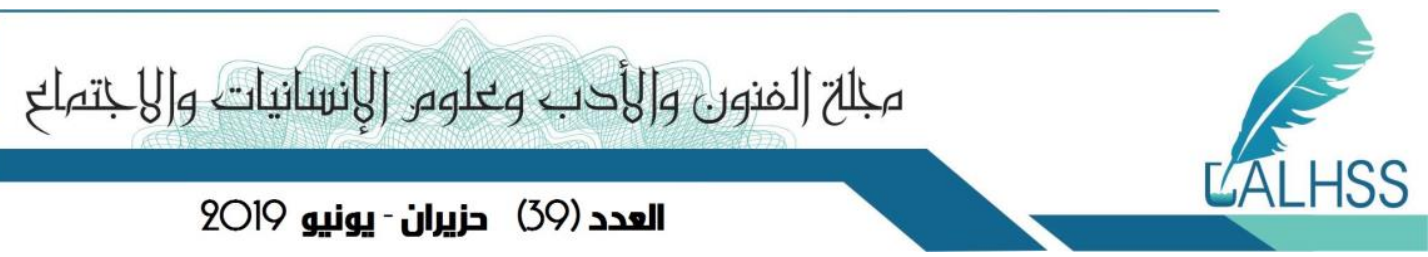

\section{INTRODUCTION}

The main objective of any productivity operation is to get high quality materials and conform to the specifications so as to meet consumer desires. The quality is a principle in which some may think it is new, but it is as old as human, because the man was still in a permanent search for a good thing, and paying attention to the quality .Quality has great care in the industrialized developed countries being of economies exporter seek to control the foreign markets. In the early twentieth century, quality control practices were limited to inspecting finished products and removing defective items. But this all changed as the result of the pioneering efforts of a young engineer named Walter A. Shewhart. In 1924 Shewhart prepared a memorandum that included a set of principles that are the basis for what is known today as process control. And his memo also contained a diagram that would be recognized as a statistical control chart. Continuing his work in quality at Bell Telephone Laboratories in USA until his retirement in 1956, he brought together the disciplines of statistics, engineering, and economics and in doing so changed the course of industrial history. Shewhart is recognized as the father of statistical quality control.

\section{Quality Control Charts}

A quality control chart (also called process chart) is a graph that shows average for the data (output) or the product fall within the common or normal range of variation if the process is under statistical control. Quality control charts were first invented by Walter A. Shewhart, and developed by him and his associate. He published a complete exposition of control charts in 1931. Which used by Shewhart in the construction of his charts. He concluded that a distribution can be transformed into a normal shape by estimating its mean and standard deviation. Shewhart's idea was whether the production process is going well and naturally and the points plotted on the chart follow a normal distribution. For these reasons, Shewhart resorted to use the normal distribution in the construction of his charts Besterfield, (2004).

Let $\mathrm{w}$ be a sample statistic that measures some quality characteristic of interest, and suppose that the mean of w is $M_{w}$ and the Standard deviation of w is $S_{w}$. Then the center line, the upper control limit, and the lower control limit become :

$$
\begin{aligned}
& C L=T=M_{w} \\
& U C L=M_{w}+3 \hat{\sigma}_{w} \\
& L C L=M_{w}-3 \hat{\sigma}_{w}
\end{aligned}
$$

\section{Classification of control charts}


Control charts may be classified into two main types, which are Montgomery, (2001):

\section{Variable Control Charts}

These charts are used in process control of products when the items produced are measurable (in one of the units of measurement).

The most important types of variable control charts can be divided into two types Montgomery, (2001):

- Average - Chart (or $\overline{\mathrm{X}}$ - chart)

- Standard Deviation- Chart (S-chart)

- Range - Chart (R-chart)

- Individual - Chart(X- chart).

- Median chart (Me- chart).

- Cumulative sum control chart(CUSUM-chart)

- Moving average chart (MA-chart)

- Moving range chart (MR-chart)

- Geometric Moving average chart (GMA-chart)

\section{Attributes Control Charts}

The attribute control charts can be classified into Montgomery, (2001) \& Besterfield, (2004):

a. Defective or nonconforming chart. p-chart (fraction nonconforming)

b. Number of Defectives (np-chart).

c. Number of Defects (C-chart)

d. U-chart (average number of nonconformities).

The following are charts used in this paper:

\section{1// Number of Defectives chart based on Three sigma( $(3 \sigma)$}

It is also possible to base a control chart on the number nonconforming rather than the fraction nonconforming. This is often called a number nonconforming (np) control chart. The parameters of this chart are as follows Besterfield, (2004):

$$
T=n \bar{P}
$$

$$
U C L=n \bar{P}+3 \sqrt{n P(1-P)} \quad 540
$$

$$
L C L=n \bar{P}-3 \sqrt{n \bar{P}(1-\bar{P})}
$$




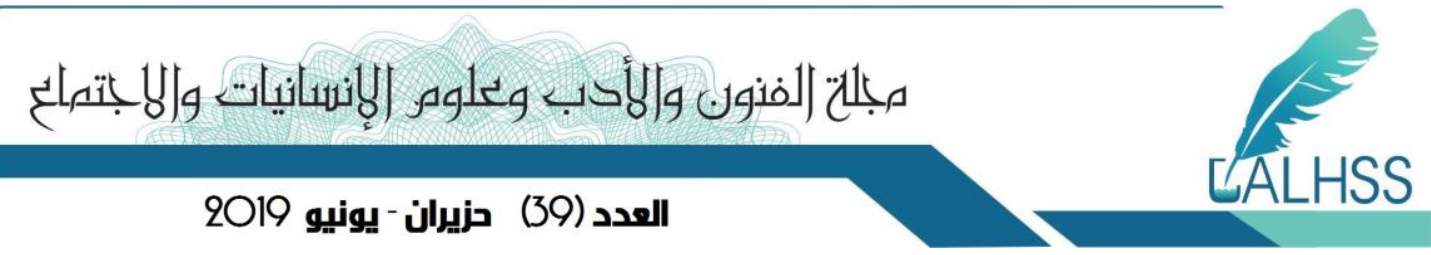

2// Number of Defectives chart based on Six Sigma ( $6 \sigma)$

Six Sigma has been successfully applied in other manufacturing sectors. Developed by Motorola in 1983, from the statistical point of view, the term six sigma is defined as having less than 3.4 defects per million opportunities (DPMO) or a success rate of 99.9997\% where sigma is a term used to represent the variation about the process average. If an organization is operating at three sigma levels for quality control, this is interpreted as achieving a success rate of $93 \%$ or 66,800 defects per million opportunities. Therefore, the six sigma method is a very rigorous quality control concept where many organizations still performs at three sigma level. If the companies practicing Six Sigma initiatives use the control limits suggested by Shewhart, then no point fall outside the control limits because of the improvement in the quality of the process. The following are steps to construction six sigma chart for Number of Defectives Radhakrishnan and Balamurugan, (2010):

\section{1/ Upper Specification Limit (USL)}

2/ Lower Specification Limit (LSL)

3/ Tolerance Level (TL): It is the difference between USL and LSL, TL = USL-LSL

4/ Process Capability $\left(C_{P}\right)$ : This is the ratio of tolerance level to six times standard deviation of the process.

$$
C_{p}=\frac{U S L-L S L}{6 \hat{\sigma}}
$$

\section{5/ Subgroup Size (n):}

In order to make control chart analysis effective, it is essential to pay due regard to the rational selection of the subgroups. It is the choice of the sample size $\mathrm{n}$ and the frequency of sampling. It is also the number of observed values in any given sample or subgroup.

\section{6/ Quality Control Constant}

To construct the Six Sigma based control limits the Quality Control constants such as are introduced in this thesis.

$$
B_{6 \sigma}=4.831
$$

\section{7/ Calculate ( $\left.\sigma_{6 \sigma}\right)$ and construction Number of Defectives Chart}




\section{مبللم (لفنون والأذب وعلوه الإنسانيات و|لإبتملع}

\section{العدد (39) ريران - يونيو 2019}

In this section a procedure to construct nP-Chart based on six sigma. Fix the Tolerance level (TL) and process capability $\left(C_{P}\right)$ to determine the process standard deviation $\left(\sigma_{6 \sigma}\right)$. Apply the value of $\sigma_{6 \sigma}$ in the control limits $n \bar{p}+B_{6 \sigma} \sigma_{6 \sigma}$, to get the Six Sigma based control limits for C-Chart. The value of $B_{6 \sigma} \sigma_{6 \sigma}$ is obtained using $p\left(z \leq z_{6 \sigma}\right)=3.4 * 10^{-6}$ and $\mathrm{z}$ is a standard normal variate. For a specified TL and $C_{P}$ of the process, the value of $\sigma$ (termed as $\sigma_{6 \sigma}$ ) is calculated from $C_{p}=\frac{T L}{6 \sigma}$ presented in Table (B) for various combinations of TL and $C_{P}$. Further the value of $B_{6 \sigma}$ is also obtained using the procedure given above and are presented in Table (C), for different values of $n$. np-Chart based on six sigma are constructed as:

$$
\begin{aligned}
& T=n \bar{p} \\
& U C L=n \bar{p}+4.831 \sigma_{6 \sigma} \\
& L C L=n \bar{p}-4.831 \sigma_{6 \sigma}
\end{aligned}
$$

\section{3// Number of Defectives chart based on regression equations}

(Ryan.Schwertman-1997) used regression equations to produce a regression-based np-chart .The control limits and central line for the np-Chart based on regression equations are calculated as follows:

$T=n \bar{P}$

$\mathrm{UCL}=0.6195+1.0052 \mathrm{n} \overline{\mathrm{p}}+2.983 \sqrt{\mathrm{n} \overline{\mathrm{p}}}$

$\mathrm{LCL}=2.9529+1.01956 \overline{\mathrm{p}}-3.2729 \sqrt{\mathrm{n} \overline{\mathrm{p}}}$

\section{4// Number of Defectives chart based on improved square root transformation,}




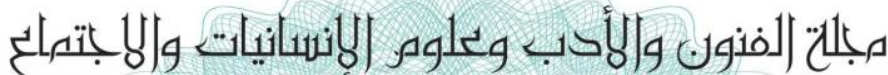

\section{العدد (39) ريران - يونيو 2019}

Let $\mathrm{X}$ be a binomial random variable with parameters $\mathrm{n}$ and $\mathrm{p}$, where $\mathrm{p}$ denotes the defect level of process, and let $\hat{P}=\frac{x}{n}$ be the sample defect level. If $\mathrm{p}$ is small, the normal approximation to the binomial distribution is inadequate, mainly due to skewness in the exact distribution. To overcome this defect, an improved square root transformation, named the ISRT, is used to construct np-chart. Control limits and central line for the np-Chart based on ISRT are calculated as follows C. C. Lin, (2006):

$$
T=\sqrt{n \bar{P}}
$$

$$
\begin{aligned}
& U C L=\sqrt{n \bar{P}}+\frac{3}{2} \sqrt{1-\bar{P}}-\frac{1}{2}\left(\frac{1-\bar{P}}{\sqrt{n \bar{P}}}\right) \\
& L C L=\sqrt{n \bar{P}}-\frac{3}{2} \sqrt{1-\bar{P}}-\frac{9}{8}\left(\frac{1-\bar{P}}{\sqrt{n \bar{P}}}\right)
\end{aligned}
$$

\section{Application}

In a manufacturing process, the number of defectives found in the inspection of (15) lots of (400) items each is given below.

\begin{tabular}{|c|c|c|}
\hline Sample & number of defectives & $\hat{p}$ \\
\hline 1 & 18 & 0.045 \\
\hline 2 & 8 & 0.020 \\
\hline 3 & 6 & 0.015 \\
\hline 4 & 0 & 0 \\
\hline 5 & 3 & 0.008 \\
\hline 6 & 0 & 0 \\
\hline 7 & 6 & 0.015 \\
\hline
\end{tabular}




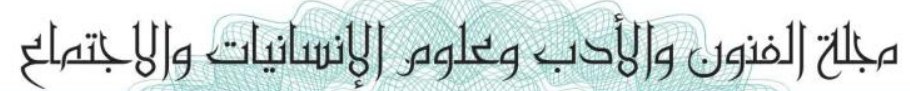

العدد (39) ريران - يونيو 2019

\begin{tabular}{|c|c|c|}
\hline 8 & 0 & 0 \\
\hline 9 & 1 & 0.002 \\
\hline 10 & 0 & 0 \\
\hline 11 & 3 & 0.008 \\
\hline 12 & 0 & 0.035 \\
\hline 13 & 2 & 0 \\
\hline 14 & 5 & 0.005 \\
\hline 15 & & 0.012 \\
\hline
\end{tabular}

$\bar{P}=\frac{\sum_{i=1}^{m} \hat{p}_{i}}{m}=\frac{\sum_{i=1}^{15} 0.165}{15}=0.011$

1// Construction of Control Limits three Sigma for Number of Defectives $T=n \bar{P}=400 * 0.011=4.4$

$U C L=n \bar{P}+3 \sqrt{n \bar{P}(1-\bar{P})}=4.4+\sqrt{4.4(1-0.011)}=10.66$

$L C L=n \bar{P}-3 \sqrt{n \bar{P}(1-\bar{P})}=4.4-\sqrt{4.4(1-0.011)}=$ Negetive $=0$ 


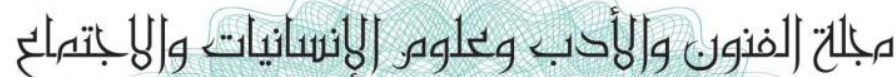

\section{العدد (39) حزيران - يونيو 2019}

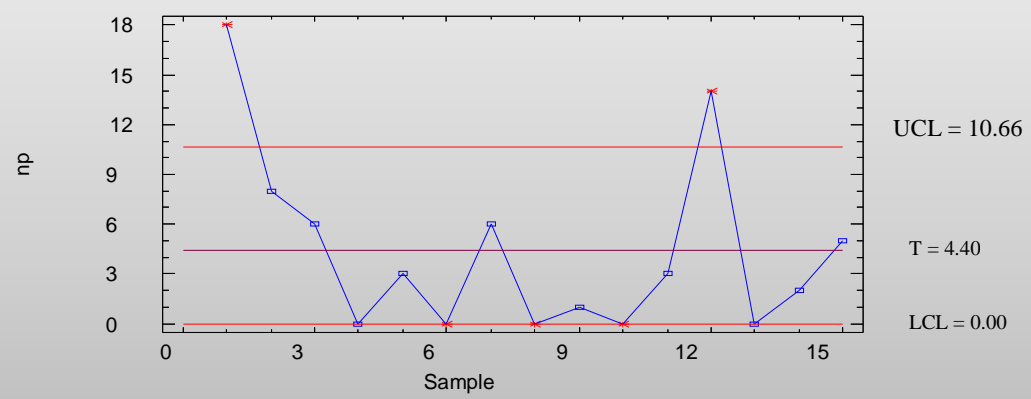

Figure 1: Number of Defectives chart based on Three Sigma

From Number of Defectives chart based on Three Sigma, since the some points fall outside the control limits, therefore it shows that process variability is out of control. Therefore process is out of control.

\section{2//Construction of Control Limits six Sigma for Number of Defectives}

For a given $(\mathrm{TL}=\mathrm{USL}-\mathrm{LSL}=18-0=18) \& \mathrm{CP}=2.5$, it is found from the Table- B that the value of $\left(\sigma_{6 \sigma}\right)$ is $(1.2)$ :

$T=n \bar{p}=4.4$

$U C L=n \bar{p}+4.831 \sigma_{6 \sigma}=4.4+4.831(1.2)=10.20$

$L C L=n \bar{p}-4.831 \sigma_{6 \sigma}=4.4-4.831(1.2)=0.072$ 


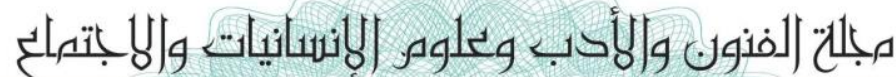

\section{العدد (39) حزيران - يونيو 2019}

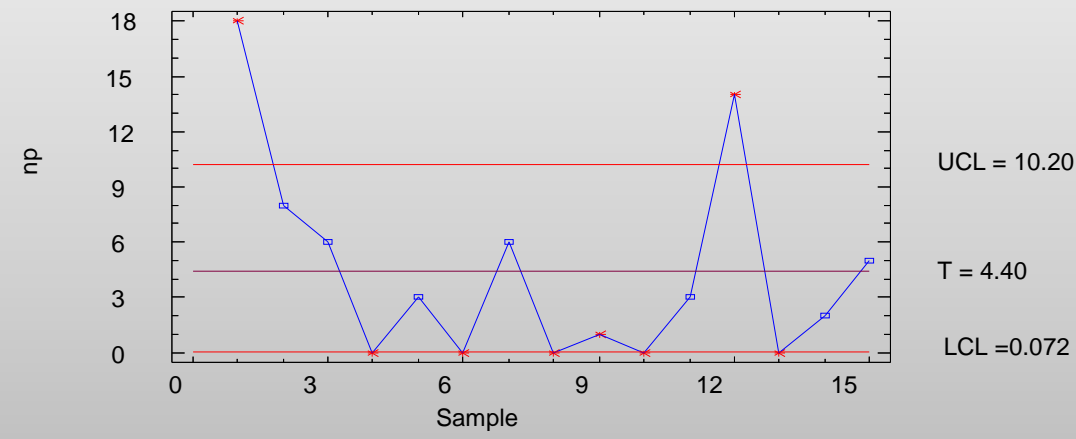

Figure 2: Number of Defectives chart based on Six Sigma

From Number of Defectives chart based on Six Sigma, since the some points fall outside the control limits, therefore it shows that process variability is out of control. Therefore process is out of control.

3// Construction of Control Limits regression equations for Number of Defectives

$$
\begin{aligned}
& T=n \bar{P}=4.4 \\
& \mathrm{UCL}=0.6195+1.0052 \mathrm{n} \overline{\mathrm{p}}+2.983 \sqrt{\mathrm{n} \overline{\mathrm{p}}}=11.29 \\
& \mathrm{LCL}=2.9529+1.01956 \mathrm{n} \overline{\mathrm{p}}-3.2729 \sqrt{\mathrm{n} \overline{\mathrm{p}}}=0.58
\end{aligned}
$$




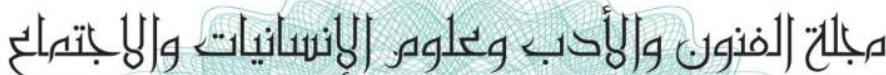

\section{العدد (39) ريران - يونيو 2019}

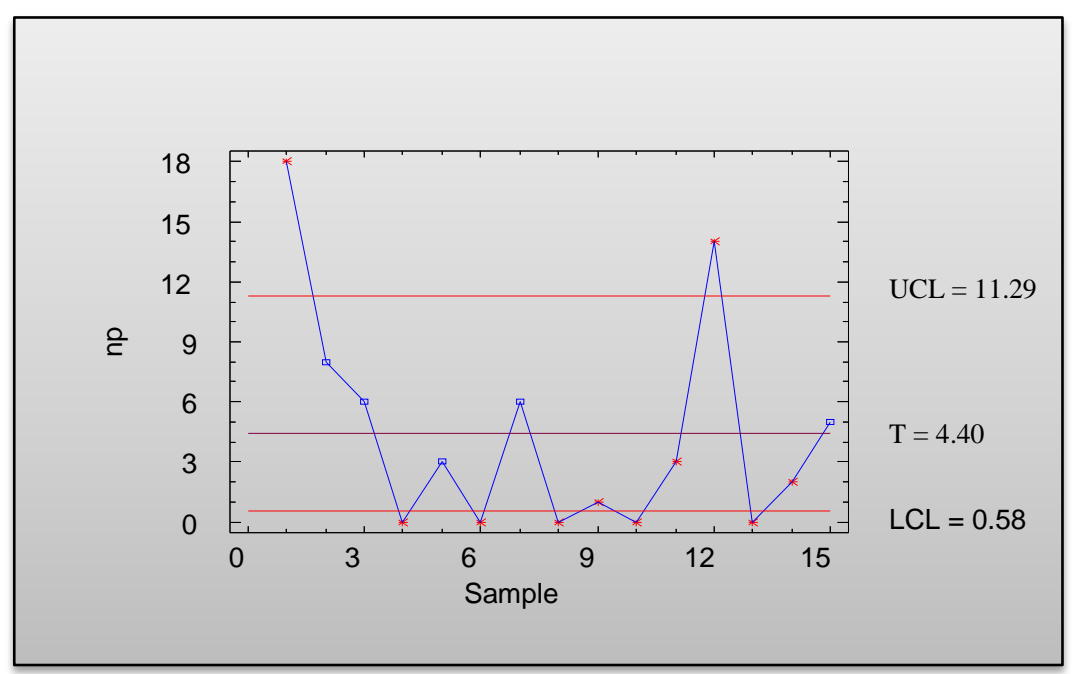

Figure 3: Number of Defectives chart based on regression equations

From Number of Defectives chart based on regression equations, since the some points fall outside the control limits, therefore it shows that process variability is out of control. Therefore process is out of control.

\section{4//Construction of Control Limits improved square root transformation} for Number of Defectives

$$
\begin{aligned}
& T=\sqrt{n \bar{P}}=\sqrt{4.4}=2.10 \\
& U C L=\sqrt{n \bar{P}}+\frac{3}{2} \sqrt{1-\bar{P}}-\frac{1}{2}\left(\frac{1-\bar{P}}{\sqrt{n \bar{P}}}\right)=3.36 \\
& L C L=\sqrt{n \bar{P}}-\frac{3}{2} \sqrt{1-\bar{P}}-\frac{9}{8}\left(\frac{1-\bar{P}}{\sqrt{n \bar{P}}}\right)=0.07
\end{aligned}
$$



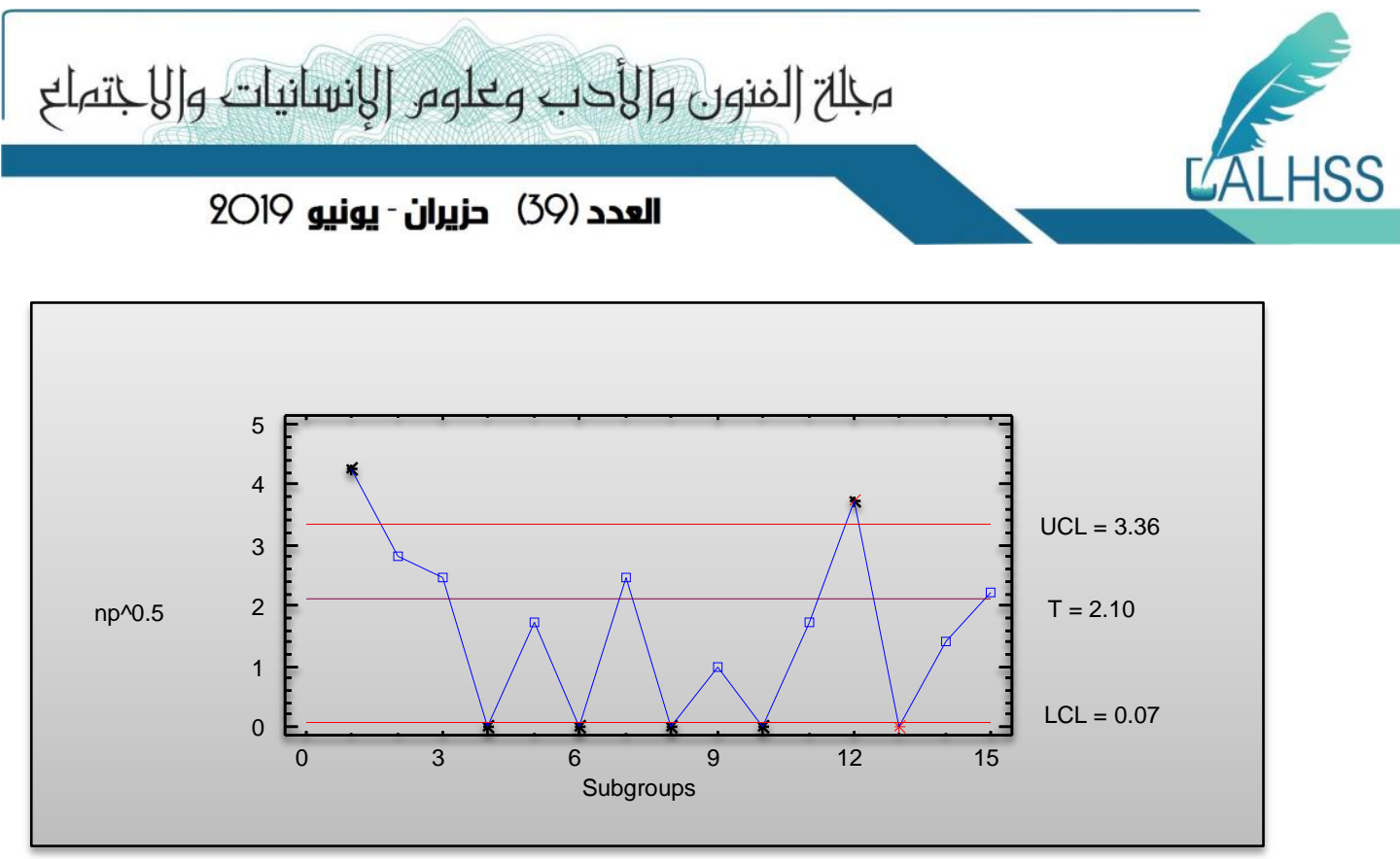

Figure 4: Number of Defectives chart based on improved square root transformation

From Number of Defectives chart based on improved square root transformation, since the some points fall outside the control limits, therefore it shows that process variability is out of control. Therefore process is out of control.

\begin{tabular}{|l|l|c|c|}
\hline \multicolumn{4}{|c|}{ Table (2): the limits control charts for all methods } \\
\hline No. & \multicolumn{1}{|c|}{ methods } & LCL & UCL \\
\hline 1 & three Sigma & 0 & 10.66 \\
\hline 2 & six Sigma & 0.07 & 10.2 \\
\hline 3 & regression equations & 0.58 & 11.29 \\
\hline 4 & improved square root transformation & 0.07 & 3.36 \\
\hline
\end{tabular}

\section{CONCLUSION}

This paper found out the followings:

1. After comparing Number of Defectives charts based upon (Three sigma, Six sigma and regression equations) to attain the Number of Defectives chart based on Six sigma, it has been proved that this method has better property than other methods, which this is due highly to the fact that the distance between control limits for Number of Defectives chart is based on six sigma and that has the smallest comparing properties than other methods. 


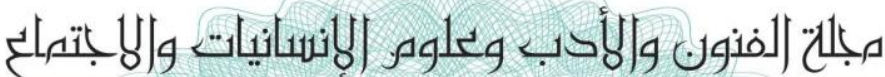

\section{العدد (39) ريران - يونيو 2019}

2. The control limits and central line values of Number of Defectives charts are based on improved square root which that can be small due to the usage of square root transformation. However, identified point on the Number of Defectives chart based on improved square root has the same Number of Defectives charts based on (Three sigma, Six sigma and regression equations). That means Number of Defectives chart based on improved square root have a good property for sensitivity and Efficiency.

3. The overall process can be out of control in all charts for the reason that some points fall out of control limits (upper \& lower).

\section{References}

1. C. C. Lin, Improved Square Root Transformation for Attribute Control Charts (2002), Tamsui Oxford Journal of Mathematical Sciences 22(1) (2006) 61-72 Aletheia University

2. D.C. Montgomery, "Introduction to statistical Quality Control (3rd Edition)", John Wiley \& Sons, Inc., New York, (2001), 217-220.

3. D. H. Besterfield, (2004) "Quality Control". 7thEdition, Prentice-Hall Inc. New York, U.S.A.

4. R.Radhakrishnan and P. Balamurugan, "Six Sigma based Control Chart for the number of Defectives", Proceedings of the 2010 International Conference on Industrial Engineering and Operations Management Dhaka, Bangladesh, January 9 - 10, 2010.

5. T. P. Ryan, and N. C. Schwertman, Optimal limits for attributes control Charts, Journal of Quality Technology 29 (1997), 86-98. 
مبلح" الفنون والأدب وعلوه الإنسانيات و|لإبتماكغ

العدد (39) حزيران - يونيو 2019

\section{APPENDIX}

\begin{tabular}{|c|c|c|c|}
\hline \multicolumn{2}{|c|}{$\sigma_{6 \sigma}$ Values for a specified $\mathrm{Cp}$ and TL } & \multicolumn{2}{|c|}{$L_{6 \sigma}$ Values for a Specified Subgroup Size (n) } \\
\hline $\begin{array}{ll}\mathrm{CP} & \mathrm{TL}=18 \\
\end{array}$ & & n & $L_{6 \sigma}$ \\
\hline 1 & 0.2363 & 2 & 3.4160 \\
\hline 1.1 & 0.2085 & 3 & 2.7891 \\
\hline 1.2 & 0.1807 & 4 & 2.4155 \\
\hline 1.3 & 0.1946 & 5 & 2.1604 \\
\hline $\begin{array}{l}1.4 \\
1.5\end{array}$ & $\frac{0.1668}{0.1529}$ & 6 & 1.9722 \\
\hline 1.6 & 0.1390 & 7 & 1.8259 \\
\hline 1.7 & 0.1390 & 8 & 1.7080 \\
\hline 1.8 & 0.1251 & 9 & 1.6103 \\
\hline 1.9 & 0.1251 & 10 & 1.5276 \\
\hline 2 & 0.1112 & & \\
\hline 2.1 & 0.1112 & & \\
\hline 2.2 & 0.1112 & & \\
\hline 2.3 & 0.0973 & & \\
\hline 2.4 & 0.0973 & & \\
\hline 2.5 & 0.0973 & & \\
\hline
\end{tabular}

